\title{
Transport of receptors, receptor signaling complexes and ion channels via neuropeptide-secretory vesicles
}

\author{
Bo Zhao ${ }^{1, *}$, Hai-Bo Wang, ${ }^{2, *}$, Ying-Jin $\mathrm{Lu}^{1}$, Jian-Wen $\mathrm{Hu}^{2}$, Lan $\mathrm{Bao}^{2}$, Xu Zhang ${ }^{1}$ \\ ${ }^{I}$ Institute of Neuroscience and State Key Laboratory of Neuroscience, Shanghai Institutes for Biological Sciences, Chinese Acad- \\ emy of Sciences, 320 Yue Yang Road, Shanghai 200031, China; ${ }^{2}$ Laboratory of Molecular Cell Biology, Institute of Biochemis- \\ try and Cell Biology, Shanghai Institutes for Biological Sciences, Chinese Academy of Sciences, 320 Yue Yang Road, Shanghai \\ 200031, China
}

Stimulus-induced exocytosis of large dense-core vesicles (LDCVs) leads to discharge of neuropeptides and fusion of LDCV membranes with the plasma membrane. However, the contribution of LDCVs to the properties of the neuronal membrane remains largely unclear. The present study found that LDCVs were associated with multiple receptors, channels and signaling molecules, suggesting that neuronal sensitivity is modulated by an LDCV-mediated mechanism. Liquid chromatography-mass spectrometry combined with immunoblotting of subcellular fractions identified 298 proteins in LDCV membranes purified from the dorsal spinal cord, including G-protein-coupled receptors, G-proteins and other signaling molecules, ion channels and trafficking-related proteins. Morphological assays showed that $\delta$-opioid receptor 1 (DOR1), $\beta 2$ adrenergic receptor (AR), $G_{\text {ai2 }}$, voltage-gated calcium channel $\alpha 2 \delta 1$ subunit and P2X purinoceptor 2 were localized in substance $P$ (SP)-positive LDCVs in small-diameter dorsal root ganglion neurons, whereas $\beta 1$ AR, Wnt receptor frizzled 8 and dishevelled 1 were present in SP-negative LDCVs. Furthermore, DOR1/ $\mathbf{G}_{\mathrm{ai2}} / \mathbf{G}_{\beta 1 \gamma 5} /$ phospholipase $C \beta 2$ complexes were associated with LDCVs. Blockade of the DOR1/ $G_{\text {ai2 }}$ interaction largely abolished the LDCV localization of $G_{\text {aiz }}$ and impaired stimulation-induced surface expression of $G_{a i 2}$. Thus, LDCVs serve as carriers of receptors, ion channels and preassembled receptor signaling complexes, enabling a rapid, activity-dependent modulation of neuronal sensitivity.

Keywords: G-protein-coupled receptors; Wnt receptors; $\mathrm{Ca}^{2+}$ channels; large dense-core vesicles; dorsal root ganglion; spinal cord

Cell Research (2011) 21:741-753. doi:10.1038/cr.2011.29; published online 15 February 2011

\section{Introduction}

Large dense-core vesicles (LDCVs) in neurons are secretory granules with electron-opaque content. Neuropeptides are stored in LDCVs and secreted in response to stimuli. In the dorsal root ganglion (DRG), a subset of small-diameter neurons express neuropeptide substance $\mathrm{P}$ (SP) and calcitonin gene-related peptide (CGRP). These neuropeptides are packed into LDCVs in the transGolgi network and transported to the afferent terminals

*These two authors contributed equally to this work.

Correspondence: Xu Zhang

Tel: +86-21-54921726; Fax: +86-21-54921762

E-mail: xu.zhang@ion.ac.cn

Received 3 August 2010; revised 22 November 2010; accepted 12 December 2010; published online 15 February 2011 for secretion in the dorsal spinal cord [1]. These afferent terminals also contain synaptic vesicles (SVs), which are responsible for secretion of the neurotransmitter glutamate. Although both SV and LDCV are regulated secretory vesicles, there are many distinctions between them. The embedded proteins in SVs are synthesized in the perikaryon, transported by synaptic precursors and incorporated into SVs via recycling in axonal terminals. In LDCVs, proteins are sorted in the trans-Golgi network and transported to axonal terminals [1-3]. Recently, proteomic strategies have been used to analyze the proteins in SVs, and trafficking proteins are the predominant components of the SV proteome [4, 5]. However, the protein composition of LDCVs remains largely unknown.

G-protein-coupled receptors (GPCRs) comprise a large family of receptors that transduce extracellular stimuli into intracellular signals. $\delta$-Opioid receptor 1 
(DOR1), which mediates the anti-nociceptive action of opioid peptides $[6,7]$, is expressed in a peptidergic subset of small DRG neurons [8-10]. In these neurons, DORs are localized in LDCVs and are effectively transported to the afferent terminals, which enables inducible surface expression following various types of stimulation [9-12]. Surface insertion of DORs can be induced by DOR agonists, which activate the heterotrimeric G-proteins in the plasma membrane and stimulate phospholipase C $\beta$ (PLC $\beta$ ) and inositol 1,4,5-trisphosphate receptor $\left(\operatorname{IP}_{3} \mathrm{R}\right)[6,9]$. However, it is not known whether G-proteins interact with GPCRs before or after agonist binding $[13,14]$. In addition, relationships among GPCRs (e.g., DORs), G-proteins and downstream signaling molecules in the secretory pathways are unclear.

The present study provides a global view of the protein composition of the membranes of LDCVs isolated from the dorsal spinal cord. We identified 298 proteins, including multiple GPCRs, ion channels and signaling molecules, associated with LDCVs. Furthermore, we found that DORs in LDCVs were preassembled with $\mathrm{G}_{\alpha i 2}, \mathrm{G}_{\beta 1 \gamma 5}$ and PLC $\beta 2$. Thus, LDCVs serve as subcellular compartments that enable activity-dependent modulation of cell membrane properties.

\section{Results}

\section{Analysis of the protein composition of $L D C V S$}

Because the density of LDCVs is distinct from other intracellular vesicles [15], we used two-step sucrosegradient centrifugation (0.3-1.2 $\mathrm{M}$ gradient followed by 1.1-2.0 $\mathrm{M}$ gradient) to isolate LDCVs from the dorsal horn of rat spinal cord. Chromogranin B (CGB) $[16,17]$ and DOR1 $[9,12]$ were used as markers for the LDCV fractions (Figure 1A). The specificity of the antibodies against DOR $1^{1-60}$ was confirmed by the absence of immunoblot signal in the spinal cord of Oprd1 exon 1-deleted mice (Supplementary information, Figure S1A). Membrane proteins extracted from the LDCV-enriched fractions, which were confirmed by electron microscopy (Supplementary information, Figure S1B), were processed by LC-MS. A total of 294 proteins were identified by LC-MS (Figure 1B). Thirty-six of these proteins were trafficking-related proteins, including the well-known LDCV residents (Supplementary information, Table S1) syntaxin 1B, Rab3a, Rab3c, synaptotagmin 2 and vesicle-associated membrane protein 1 (VAMP1) [18-21]. Importantly, 8 GPCRs, 10 ion channels, 6 transporters and 70 signaling molecules were detected in the LDCVenriched fractions (Supplementary information, Table S1).

We noticed that DOR1 $[9,12]$ and serotonin receptor
1D (5-HT-1D) [22], which have been detected in LDCVs in small DRG neurons, were not detected by the LC-MS method because of low expression levels. To compensate for this methodological disadvantage, we carried out immunoblot analysis of 13 GPCRs, which are expressed in DRG neurons [23], in the subcellular fractions. After the second sucrose-gradient (1.1-2.0 M) centrifugation, CGRP was enriched in the DOR1-positive fraction, which was concentrated from the CGB- and DOR1containing fractions obtained through the first sucrosegradient (0.3-1.2 M) centrifugation (Figure 1C). The CGRP-containing fraction specifically represents the LDCV-concentrated fraction because neither Cyto C, a mitochondrial protein, nor protein disulfide isomerase (PDI), an endoplasmic reticulum protein, was enriched in this fraction (Figure 1C). The LDCV-enriched fractions were also not contaminated with the plasma membrane proteins, as TrkA, transferring receptor, and caveolin-1, a lipid raft marker, were not found in the fraction (Supplementary information, Figure S1C). In addition to DOR1 and 5-HT-1D, $\beta 1$ adrenergic receptor ( $\beta 1 \mathrm{AR}), \beta 2 \mathrm{AR}$, neurotensin receptor 2 (NTR-2) and metabotropic glutamate receptor 3 (mGluR3) were more abundant in the LDCV-enriched fraction labeled by CGRP; however, mGluR7, galanin receptor 1, and prostaglandin $\mathrm{E}_{2}$ receptor EP2, EP3 and EP4 subtypes were not enriched (Figure $1 \mathrm{C}$ and Supplementary information, Figure S1C). Moreover, the LDCV localization of B1 bradykinin receptor (B1 BKR), frizzled 8 (Fzd8), voltage-gated calcium channel (VGCC) $\alpha 2 \delta 1$, voltage-dependent anionselective channel protein 1 , excitatory amino acid transporter 2 (EAAT2), $\mathrm{G}_{\alpha \mathrm{i} 2}$ and $\mathrm{G}_{\beta 1}$ that we observed by LCMS was also confirmed by immunoblot (Figure $1 \mathrm{C}$ and Supplementary information, Figure S1C). Although these proteins were present in the LDCV-enriched fraction, the differences in their immunoblot patterns might have been due to their differential subcellular distributions or different expression profiles in afferent terminals and local neurons in the spinal cord. For instance, DOR1, 5-HT$1 D, G_{\alpha i 2}$ and $G_{\beta 1}$ were found in both the LDCV-enriched pellet (P2) and the non-LDCV supernatant (S2) of the homogenate (Figure 1C), suggesting that they are present in LDCVs, microvesicles of constitutive secretory pathways and other organelles. Taken together, these results suggest that the LDCV membrane contains many GPCRs and ion channels along with G-proteins and other signaling molecules.

\section{LDCV localization of GPCRs, signaling molecules and ion channels}

We used morphological approaches to further analyze the subcellular localization of the proteins detected 
A
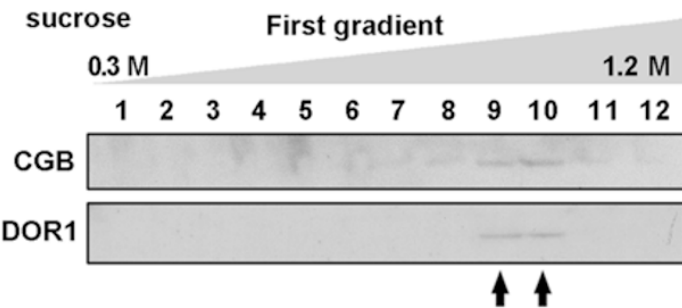

sucrose Second gradient

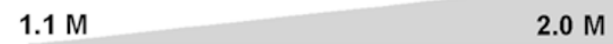

$\begin{array}{llllllllllll}1 & 2 & 3 & 4 & 5 & 6 & 7 & 8 & 9 & 10 & 11 & 12\end{array}$
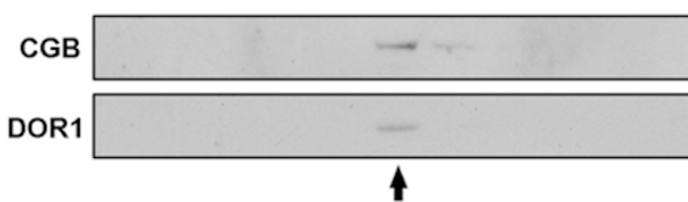

B

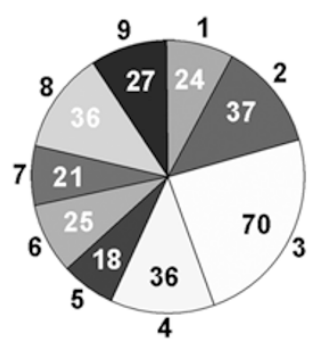

1. GPCRs, channels and transporters

2. other membrane proteins

3. signaling molecules

4. trafficking related proteins

5. cytoskeleton proteins

6. proteins associated with ER or Golgi complex and secreted proteins

7. metabolic enzymes

8. others

9. novel proteins
C
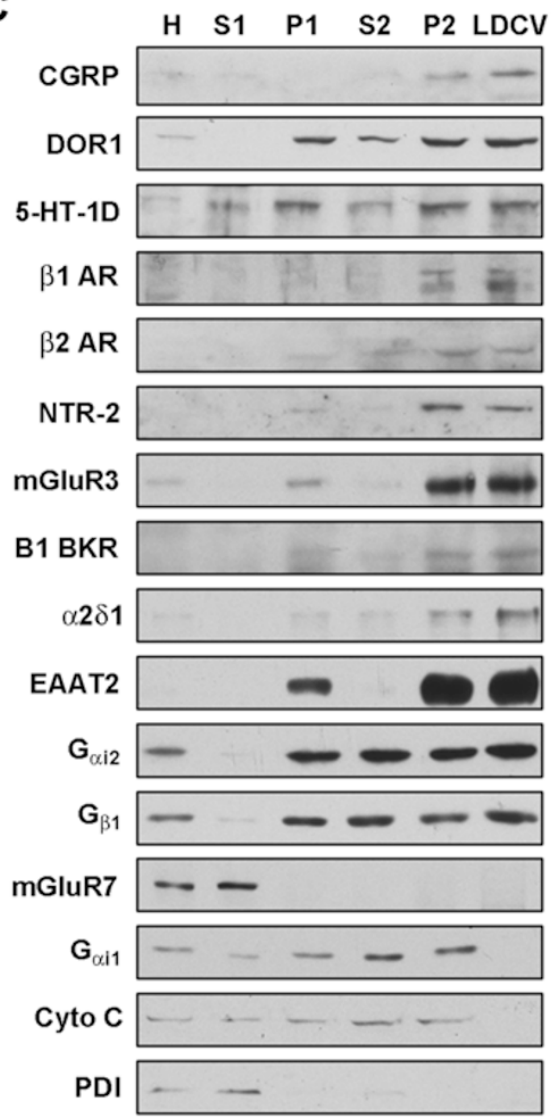

Figure 1 Isolation of LDCVs and identification of LDCV-associated proteins. (A) Isolation of LDCVs from the spinal dorsal horn of rats by two-step sucrose-gradient centrifugation. After the first sucrose-gradient (0.3-1.2 M) centrifugation, the CGBand DOR1-containing LDCV fractions were collected in tubes 9 and 10 (arrows) and subjected to the second sucrose-gradient (1.1-2.0 M) centrifugation to obtain the LDCV-enriched fraction in tube 7 (arrow). (B) Pie graph showing the categories of LDCV membrane-associated proteins detected by LC-MS and the number of proteins in each category. (C) Immunoblotting of subcellular fractions shows the distribution profiles of the indicated proteins. $\mathrm{H}$, homogenate; S1 and $\mathrm{P} 1$, the supernatant and pellet, respectively, from homogenate centrifuged for $15 \mathrm{~min}$ at $10500 \times \mathrm{g}$, with LDCVs enriched in P1; S2 and P2, nonLDCV- and LDCV-containing fractions, respectively, after the first sucrose-gradient centrifugation; LDCV, LDCV-enriched fraction obtained by the second sucrose-gradient centrifugation. Material from tubes 9 and 10 after the first sucrose centrifugation were mixed and centrifuged at $100000 \times \mathrm{g}$. The P2 fraction was collected from re-suspension of the pellet, and fraction S2 was a mixture of collected material from tubes 1-8 and 11-13 after the first sucrose centrifugation. The LDCV fraction corresponds to material collected from tube 7 of the second sucrose centrifugation. Protein levels were quantified using the Bradford assay, and equivalent amounts of protein were loaded in all lanes of the gels. One immunoblot representative of three independent experiments is shown.

above. A previous study has shown that $\sim 70 \%$ of LDCVs contain SP and/or CGRP in afferent terminals [24]. Double immunofluorescence staining showed that DORs were present in SP- and CGRP-positive LDCVs in small DRG neurons in mice (Figure 2A and Supplementary information, Figure S2A). This immunostaining pattern, which was shown with antibodies against DOR $1^{3-17}$, was abolished by the deletion of Oprd1 exon 1 in mice (Supplementary information, Figure S2A). Furthermore, $\beta 2$ AR, $G_{\text {aiz }}$, PLC $\beta 2$, VGCC $\alpha 2 \delta 1$ and P2X purinoceptor
$2\left(\mathrm{P} 2 \mathrm{X}_{2}\right)$ were present in SP-positive LDCVs in small DRG neurons (Figure 2A). At the ultrastructural level, immunogold labeling in the spinal lamina II showed that $27 \%$ of gold particle labeling for DOR $1,23 \%$ for $\beta 2 \mathrm{AR}$, $28 \%$ for $\mathrm{G}_{\alpha \mathrm{i} i}, 27 \%$ for PLC $\beta 2,30 \%$ for VGCC $\alpha 2 \delta 1$ and $37 \%$ for $\mathrm{P}_{2} \mathrm{X}_{2}$ were associated with LDCVs in the afferent terminals (20 LDCV-containing terminals stained for each protein) (Figure 2B and Supplementary information, Figure S2B), which often form the glomerulus structures [24]. Because the average area of LDCVs contributed to 
A

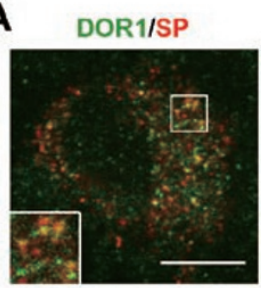

PLCB2/SP

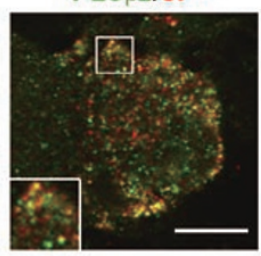

B

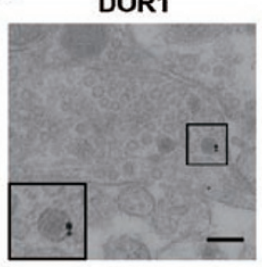

PLC $\beta 2$

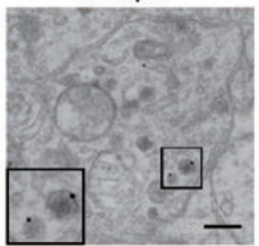

B2 ARISP

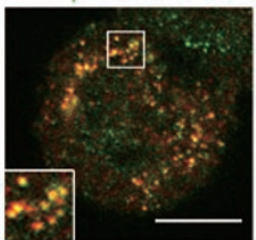

$\alpha 2 \delta 1 / \mathrm{SP}$

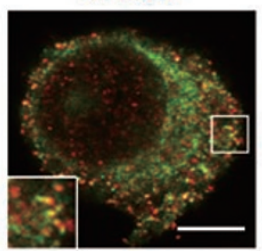

B2 AR

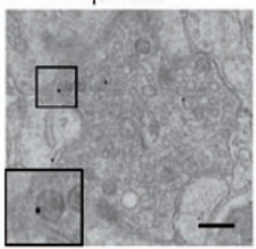

$\alpha .2 \delta 1$

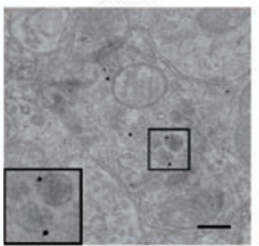

$\mathrm{G}_{\mathrm{oi} 2} / \mathrm{SP}$

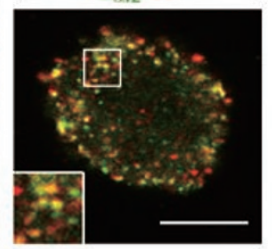

$\mathrm{P} 2 \mathrm{X}_{2} / \mathrm{SP}$

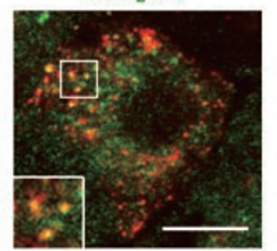

$\mathbf{G}_{\alpha \mathbf{\alpha} 2}$

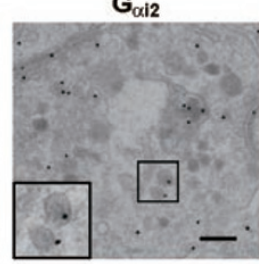

$\mathrm{P}_{2} \mathrm{X}_{2}$

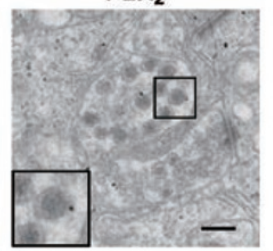

Figure 2 Localization of receptors, signaling molecules and ion channels in SP-positive LDCVs. (A) Double immunofluorescence staining shows the distribution of DOR1, $\beta 2 A R, G_{\alpha i 2}$, PLC $\beta 2$, VGCC $\alpha 2 \delta 1$ and $P 2 X_{2}$ (in green) in SP-positive (in red) LDCVs in small DRG neurons of mice. Scale bar, $8 \mu \mathrm{m}$. (B) Post-embedding immunogold (10 or $15 \mathrm{~nm}$ in diameter) staining shows that DOR1, $\beta 2$ AR, $G_{\alpha i 2}, P L C \beta 2, V G C C \alpha 2 \delta 1$ and P2X are localized near the surface of LDCVs in afferent terminals in lamina II of the mouse spinal cord. Scale bar, $200 \mathrm{~nm}$.

$\sim 2 \%$ of the area of the afferent terminals, the intensity of immunogold labeling associated with LDCVs was about 10 times higher than the labeling intensity in the rest of the afferent terminals. Importantly, no significant immunogold labeling could be detected without primary antibodies (Supplementary information, Figure S2C).

Interestingly, in SP- or CGRP-positive DRG neurons, $\beta 1$ AR, Fzd8 and dishevelled 1 (Dvl1), a signaling molecule downstream of Fzd8, were localized in the vesicles that did not contain SP or CGRP (Figure 3A and Supplementary information, Figure S2D). At the ultrastructural level, $21 \%$ of gold particle labeling for $\beta 1 \mathrm{AR}, 28 \%$ for Fzd8 and 23\% for Dvl1 were associated with LDCVs (20 LDCV-containing terminals stained for each protein)

(Figure 3B and Supplementary information, Figure S2B). This suggests that these proteins are localized in another subset of LDCVs in small DRG neurons.

To further evaluate the specificity of the LDCV localization that we observed by immunostaining, we transfected PC12 cells, which contain LDCVs and express peptides $[9,11]$, with the plasmids expressing Myctagged receptors, ion channels and G-proteins. Immunostaining with anti-Myc antibodies showed that $\beta 2$ ARMyc, $\mathrm{G}_{\alpha \mathrm{i} 2}$-Myc, VGCC $\alpha 2 \delta 1-\mathrm{Myc}, \mathrm{P} 2 \mathrm{X}_{2}$-Myc, Dvl1Myc, Myc-DOR1, $\mathrm{K}_{\mathrm{v}}-\beta 2-\mathrm{Myc}$ and B1 BKR-Myc were associated with vesicular structures in the cytoplasm, whereas the Myc-tagged $\mathrm{G}_{\mathrm{o}}$ type of G-protein was mainly distributed on the cell surface (Figure 4A and Supplementary information, Figure S3A). Furthermore, double immunostaining showed that the vesicular structures that contained receptors or channel subunits were not positive for the early endosome marker EEA1 in transfected PC12 cells, suggesting that the vesicular structures were not endosomes (Figure 4B and Supplementary information, Figure S3B). In microsomes of transfected PC12 cells, pre-embedding immunogold-silver staining showed that both DOR1 tagged with HA or Myc [9, 11, 25] and $\beta 2$ AR tagged with Myc (Supplementary information, Figure S3C) were associated with LDCVs, but not lysosomes. The LDCV localization of other receptors, ion channels and transporters is shown in Supplementary information, Figure S3D. Together with the results of LC-

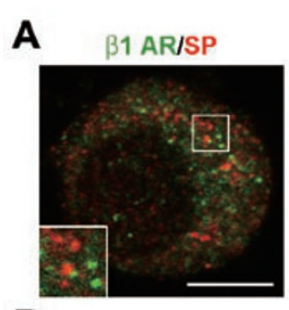

B

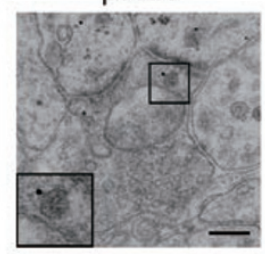

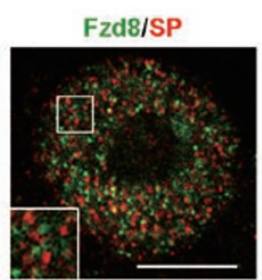

Fzd8

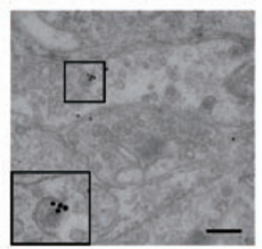

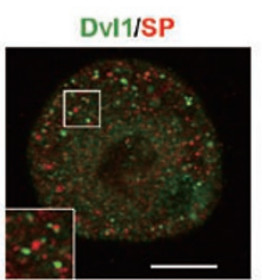

Dvl1

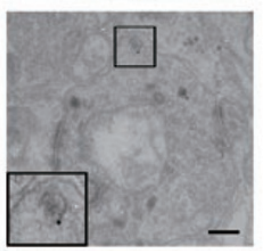

Figure 3 Localization of receptors and signaling molecules in SP-negative LDCVs. (A) Double immunofluorescence staining shows the distribution of $\beta 1 \mathrm{AR}, \mathrm{Fzd} 8$ and Dvl1 (in green) in SP (in red)-negative vesicles in small DRG neurons of mice. Scale bar, $8 \mu \mathrm{m}$. (B) Post-embedding immunogold (10 or $15 \mathrm{~nm}$ in diameter) staining shows that $\beta 1 \mathrm{AR}, \mathrm{Fzd} 8$ and Dvl1 are localized near the surface of LDCVs in afferent terminals in lamina II of mouse spinal cord. Scale bar, $200 \mathrm{~nm}$. 
A

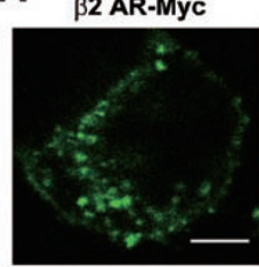

P2X - Myc

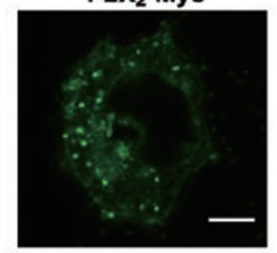

B

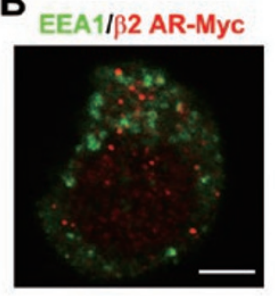

$\mathbf{G}_{\alpha \mathrm{i} 2}-\mathbf{M y c}$

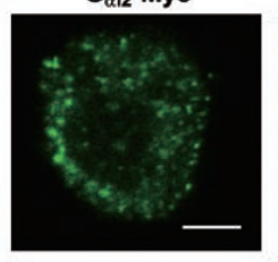

Dvl1-Myc

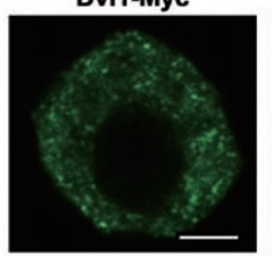

EEA1/G $\mathbf{G}_{\mathrm{i} 2}-\mathrm{Myc}_{\mathrm{c}}$

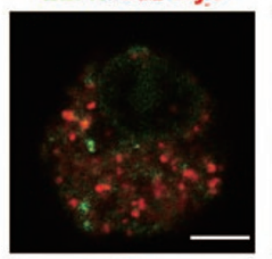

$\alpha 2 \delta 1-$ Myc

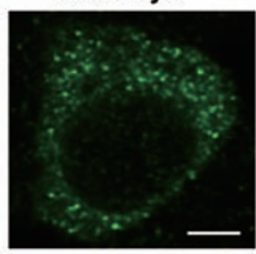

Go-Myc

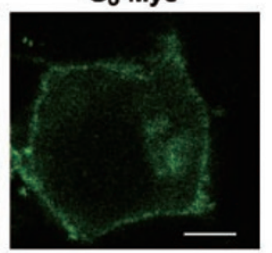

EEA1/ $\alpha 2 \delta 1-M y c$

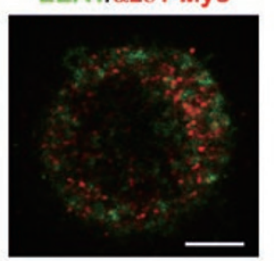

Figure 4 Distribution of some receptors, ion channel subunits and signaling molecules in transfected PC12 cells. (A) Immunostaining with antibodies against Myc in transfected PC12 cells shows that $\beta 2$ AR-Myc, $G_{a i 2}$-Myc, VGCC $\alpha 2 \delta 1-M y c, ~ P 2 X_{2}-M y c$ and Dvl1-Myc are distributed primarily in vesicular structures in the cytoplasm, whereas $G_{0}-M y c$ is localized on the cell surface. Scale bar, $4 \mu \mathrm{m}$. (B) Immunostaining with antibodies against Myc shows that in transfected PC12 cells $\beta 2$ AR-Myc, $G_{\text {ai2 }}-M y c$ and VGCC $\alpha 2 \delta 1-M y c$ (in red) are not co-localized with early endosome marker EEA1 (in green). Scale bar, $4 \mu \mathrm{m}$.

MS and immunoblotting, the LDCV-localized proteins confirmed by morphological analyses are summarized in Table 1. These results indicate that, in addition to the storage of neuropeptides, LDCVs carry multiple receptors, ion channels and signaling molecules.

Co-localization of receptors with signaling molecules in LDCVS

We were also interested in the potential correlation

Table 1 Identified LDCV-associated proteins that were confirmed by immunostaining

\begin{tabular}{|c|c|c|c|c|}
\hline Protein & LC-MS & Immunoblotting & Immunostaining & Reported \\
\hline \multicolumn{5}{|c|}{ GPCRs and Wnt receptors } \\
\hline DOR1 & & + & + & {$[12]$} \\
\hline B1 BKR & + & + & + & \\
\hline$\beta 1 \mathrm{AR}$ & & + & + & \\
\hline \multicolumn{5}{|c|}{ Signaling molecules } \\
\hline $\mathrm{G}_{\mathrm{ai2} 2}$ & + & + & + & \\
\hline $\mathrm{G}_{\beta 1}$ & + & + & + & \\
\hline $\mathrm{G}_{\gamma 5}$ & + & & + & \\
\hline Axin & & + & + & \\
\hline \multicolumn{5}{|l|}{ Channels } \\
\hline VGCC $\alpha 2 \delta 1$ & + & + & + & \\
\hline $\mathrm{P} 2 \mathrm{X}_{2}$ & + & & + & \\
\hline $\mathrm{IP}_{3} \mathrm{R} 3$ & + & & + & {$[50]$} \\
\hline TRPV2 & + & & + & \\
\hline $\mathrm{K}_{\mathrm{V}}-\beta 2$ & + & & + & \\
\hline \multicolumn{5}{|l|}{ Transporters } \\
\hline EAAT2 & + & + & + & \\
\hline
\end{tabular}

Abbreviations: TRPV2, transient receptor potential cation channel subfamily V member $2 ; \mathrm{K}_{\mathrm{V}}-\beta 2$, voltage-gated potassium channel subunit $\beta 2$; VGAT, vesicular inhibitory amino acid transporter 
between the identified receptors and downstream signaling molecules. DORs mediate physiological and pharmacological effects through activation of G-proteins, such as $\mathrm{G}_{\alpha \mathrm{i} 2}$ and $\mathrm{G}_{\beta 1}$ [26-28], and the downstream PLC $\beta /$ $\mathrm{IP}_{3} \mathrm{R}$ pathway [9]. Both LC-MS and morphological results show that DOR1, $\mathrm{G}_{\text {oi2 }}, \mathrm{G}_{\beta 1}, \mathrm{G}_{\gamma 5}, \mathrm{PLC} \beta 2$ and $\mathrm{IP}_{3} \mathrm{R} 3$ were associated with LDCVs. Double immunostaining showed that DOR1 and $\mathrm{G}_{\mathrm{\alpha i} 2}$ were co-localized in vesicles in small DRG neurons (Figure 5A). Moreover, $\mathrm{G}_{\text {oi2 }}$ was co-localized with $\mathrm{G}_{\beta 1}, \mathrm{G}_{\gamma 5}$ and PLC $\beta 2$ in vesicles (Figure $5 \mathrm{~A})$. More definitive evidence for the co-localization of DOR1 with its downstream signaling molecules in LDCVs was obtained with post-embedding double immunogold labeling. At the ultrastructural level, $\mathrm{G}_{\mathrm{ai} 2}$ colocalized with DOR1, $\mathrm{G}_{\beta 1}, \mathrm{G}_{\gamma 5}$ and PLC $\beta 2$ in LDCVs in afferent terminals (Figure 5B). Fifty-three percent of the $\mathrm{G}_{a \mathrm{i} 2}$-immunoreactive LDCVs $(n=100)$ in afferent terminals were also positive for DOR 1 , and $37 \%, 23 \%$ and $35 \%$ were also positive for $\mathrm{G}_{\beta 1}, \mathrm{G}_{\gamma 5}$ and PLC $\beta 2$, respec- tively.

Furthermore, we noticed that molecules related to the Wnt signaling pathway were present in LDCVs. As a Wnt receptor, Fzd8 activates its downstream signaling molecules Dvl1 and axin/glycogen synthase kinase 3 $3 /$ $\beta$-catenin complex [29-31]. The LC-MS assay showed the presence of Fzd8, Dvll and $\beta$-catenin in the LDCV membrane-associated proteins, and immunoblotting of subcellular fractions showed an enrichment of Fzd8 and axin in the LDCV-containing fraction (Supplementary information, Figure S1C and Table S1). Double immunostaining showed co-localization of Fzd8 with Dvl1 and axin in vesicles in small DRG neurons (Figure 5C). Post-embedding double immunogold labeling showed that $53 \%$ and $60 \%$ of the Fzd8-immunoreactive LDCVs $(n=100)$ in the afferent terminals were also positive for Dvl1 and axin, respectively (Figure 5D). Co-localization of these receptors and their downstream signaling molecules in LDCVs suggests that the preassembled receptor/
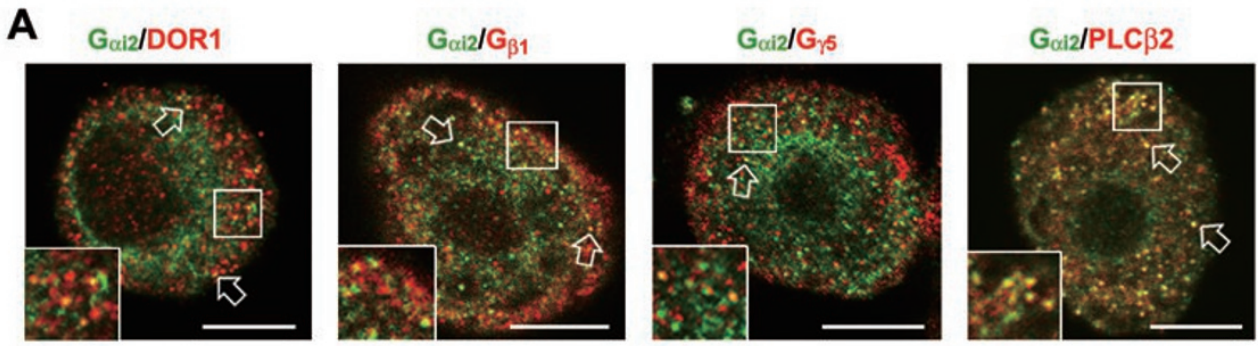

B
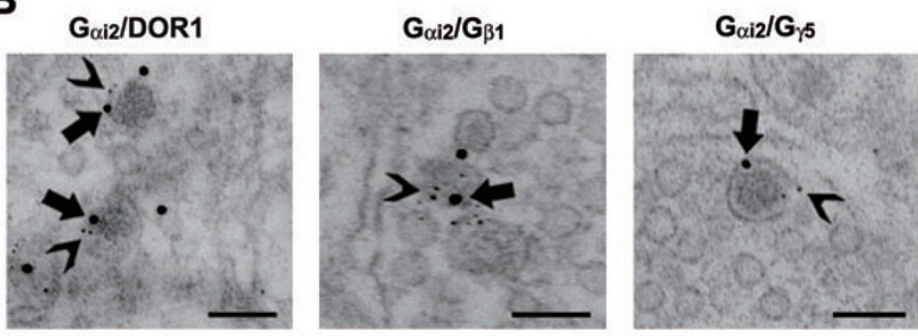

$\mathbf{G}_{\alpha i 2 / P L C \beta 2}$
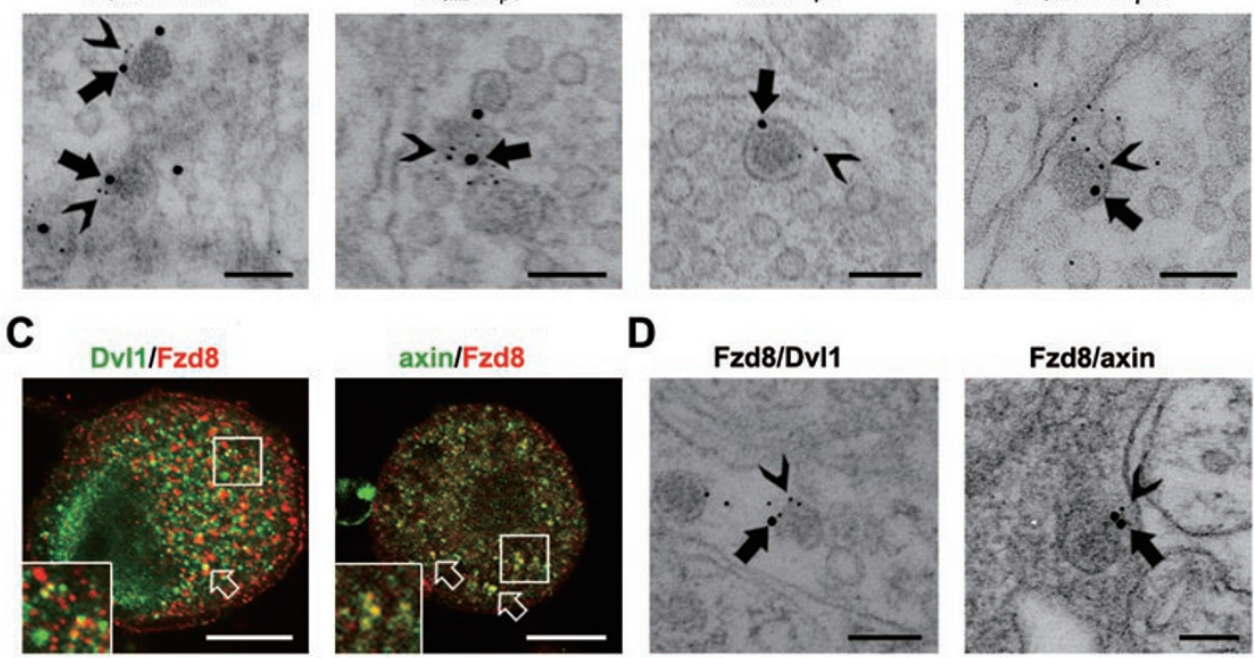

Fzd8/axin

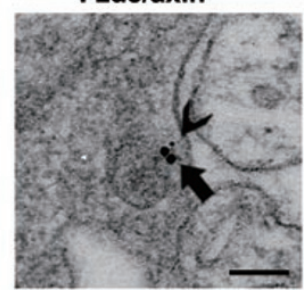

Figure 5 Co-localization of receptors and signaling molecules in LDCVs. (A) Double immunostaining shows co-localization of $G_{\text {ai2 }}$ (in green) with DOR1, $G_{\beta 1}, G_{\gamma 5}$ and PLC $\beta 2$ (in red) in vesicles (arrows) in small DRG neurons of mice. Scale bar, $8 \mu \mathrm{m}$. (B) Immunogold labeling shows co-localization of $\mathrm{G}_{\alpha i 2}\left(15 \mathrm{~nm}\right.$ gold particles (GP), arrows) with DOR1, G ${ }_{\beta 1}, \mathrm{G}_{\gamma 5}$ and PLC $\beta 2$ (5 $\mathrm{nm}$ GP, arrowheads) in LDCVs in afferent terminals in lamina II of mouse spinal cord. Scale bar, $100 \mathrm{~nm}$. (C) Fzd8 (in green) is co-localized with Dvl1 and axin (in red) in vesicles (arrows) in small DRG neurons. Scale bar, $8 \mu \mathrm{m}$. (D) Fzd8 (15 nm GP, arrows) is also co-localized with Dvl1 and axin ( $5 \mathrm{~nm} \mathrm{GP}$, arrowheads) in LDCVs in afferent terminals. Scale bar, $100 \mathrm{~nm}$. 
A

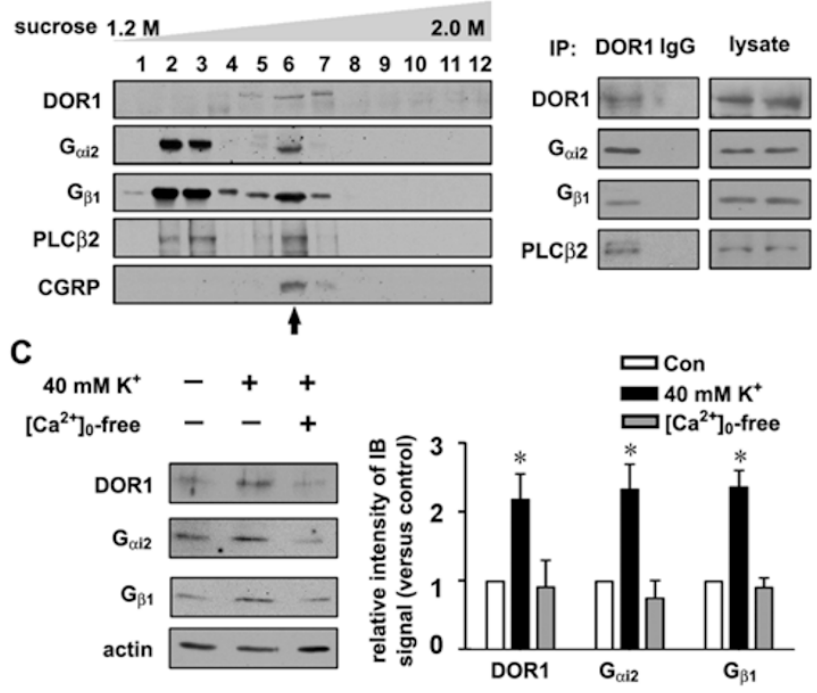

Figure 6 Preassembled DOR1/signaling molecule complexes in LDCVs. (A) In the protein fractions obtained via sucrosegradient centrifugation, DOR1, $\mathrm{G}_{\alpha \mathrm{i} 2}, \mathrm{G}_{\beta 1}$ and PLC $\beta 2$ can be seen in the CGRP-containing vesicle fraction (arrow). (B) Proteins from the LDCV-enriched fraction were immunoprecipitated with DOR1 antibodies or IgG. Co-IP shows that DORs are associated with $G_{\text {oi } 2}, G_{\beta 1}$ and PLC $\beta 2$. Three independent experiments were performed. (C) Cell-surface biotinylation and immunoblotting shows that the levels of DOR1, $G_{\text {ai2 }}$ and $G_{\beta 1}$ on the cell surface of cultured mouse DRG neurons are elevated by $\mathrm{K}^{+}$induced depolarization in the presence of extracellular $\mathrm{Ca}^{2+}$. ${ }^{*} P$ $<0.05$ versus control $(n=6)$.

signaling molecule complex might exist in LDCVs.

Preassembled DOR $1 / G_{\text {ai } 2} / G_{\beta 1} / P L C \beta 2$ complexes in $L D$ CVS

To investigate whether preassembled receptor/signaling molecule complexes exist in LDCVs, we examined whether DOR1 and its downstream signaling molecules could form complexes in LDCVs. DOR1, $G_{\alpha i 2}, G_{\beta 1}$ and PLC $\beta 2$ were present in the fractions containing CGRPpositive LDCVs after the second sucrose-gradient purification (Figure 6A). Co-immunoprecipitation (IP) with the proteins extracted from the LDCV-enriched fractions showed an association between DOR1 and $\mathrm{G}_{\mathrm{\alpha i2} 2}, \mathrm{G}_{\beta 1}$ and PLC $\beta 2$ (Figure 6B), suggesting the existence of receptor/ signaling molecule complexes. The LDCV-associated DORs are recruited to the cell surface by $\mathrm{K}^{+}$-induced membrane depolarization [9]. In the presence of extracellular $\mathrm{Ca}^{2+}\left(\left[\mathrm{Ca}^{2+}\right]_{0}\right)$, 5-min $\mathrm{K}^{+}$stimulation $(40 \mathrm{mM}$ $\mathrm{KCl}$ ) increased the surface expression of $\mathrm{G}_{\alpha \mathrm{i} 2}, \mathrm{G}_{\beta 1}$, and DOR1 in dissociated DRG neurons (Figure 6C). Thus, DOR1 and downstream signaling molecules can be pre- assembled as a complex in LDCVs, which enables rapid modulation of the membrane properties in response to stimulation.

Interruption of the DOR $1 / G_{\text {oiz }}$ interaction causes disassociation of $G_{\text {oiz }}$ from $L D C V S$

We investigated whether the interaction between DOR 1 and $\mathrm{G}_{\text {ai2 }}$, which is a cytosolic protein, was required for recruiting $\mathrm{G}_{\mathrm{\alpha i} 2}$ to LDCVs. DOR1 belongs to the rhodopsin family of GPCRs, and $\mathrm{G}_{\alpha}$ directly interacts with the third intracellular loop (IL3) of these GPCRs [32, 33]. To disrupt the $D O R 1 / G_{\text {oi }}$ interaction, we constructed a GST fusion protein (GST-TAT-IL3) containing a peptide corresponding to the IL3 of DOR1 and the TAT peptide (YGRKKRRQRRR), which is used for intracellular delivery of proteins [34] (Figure 7A). Bath-applied GSTTAT-IL3 (150 nM) permeated into cultured mouse DRG neurons in a time-dependent manner (Supplementary information, Figure S4A). Co-IP experiments showed that exposure to GST-TAT-IL3 for $6 \mathrm{~h}$ attenuated the interaction between DOR1 and $\mathrm{G}_{\text {ai2 }} / \mathrm{G}_{\beta 1}$ in cultured DRG neurons (Figure 7B). Moreover, GST-TAT-IL3 was detected in the extracts from the DRG and the spinal cord of mice after intraperitoneal (i.p.) injection $(25 \mathrm{mg} / \mathrm{kg} /$ injection, four injections within $8 \mathrm{~h}$ ) (Supplementary information, Figure S4B). Thus, GST-TAT-IL3 can be used as a molecular tool to interrupt the DOR $1 / \mathrm{G}_{\alpha \mathrm{i} 2}$ interaction.

We also investigated whether the disruption of the DOR $1 / G_{a i 2}$ interaction could alter the distribution of $\mathrm{G}_{\alpha \mathrm{i} 2}$ in LDCVs and the stimulus-induced surface expression of $\mathrm{G}_{\mathrm{\alpha i2}}$. Electrical stimulation can efficiently trigger LDCV exocytosis, neuropeptide release and surface delivery of DORs $[10,35]$. We found that $10-\mathrm{Hz}$ electrical stimulation for 5 min elevated the levels of DOR 1 and $G_{\text {ai2 }}$ on the cell surface of neurons dissociated from mouse DRGs (Figure 7C). After incubation with GSTTAT-IL3 (150 nM) for $6 \mathrm{~h}, 10-\mathrm{Hz}$ electrical stimulation enhanced surface expression of DOR1, but not $G_{a i 2}$ (Figure 7C), indicating a reduction in the amount of $\mathrm{G}_{\mathrm{aiz}}$ in the regulated secretory pathway. Furthermore, the sucrose gradient experiments showed that GST-TATIL3 (i.p., $25 \mathrm{mg} / \mathrm{kg}$, once a day for 4 days) increased the amount of $G_{\text {ai2 }}$ in the fractions lighter than the CGRPcontaining LDCV fraction; however, the DOR1-containing fractions were not shifted (Figure 7D). The applied GST-TAT-IL3 also reduced the axonal transport of $\mathrm{G}_{\alpha \mathrm{i} 2}$ to the dorsal spinal cord (Supplementary information, Figure S4C). Immunogold labeling showed that the LDCVassociated $G_{\alpha i 2}$ labeling was reduced in the $G_{\alpha i 2}$-positive afferent terminals in the spinal lamina II after GST-TATIL3 administration (i.p., $25 \mathrm{mg} / \mathrm{kg}$ ) (Figure 7E). These results indicate that the DOR $1 / \mathrm{G}_{\text {ai2 }}$ interaction is impor- 
A

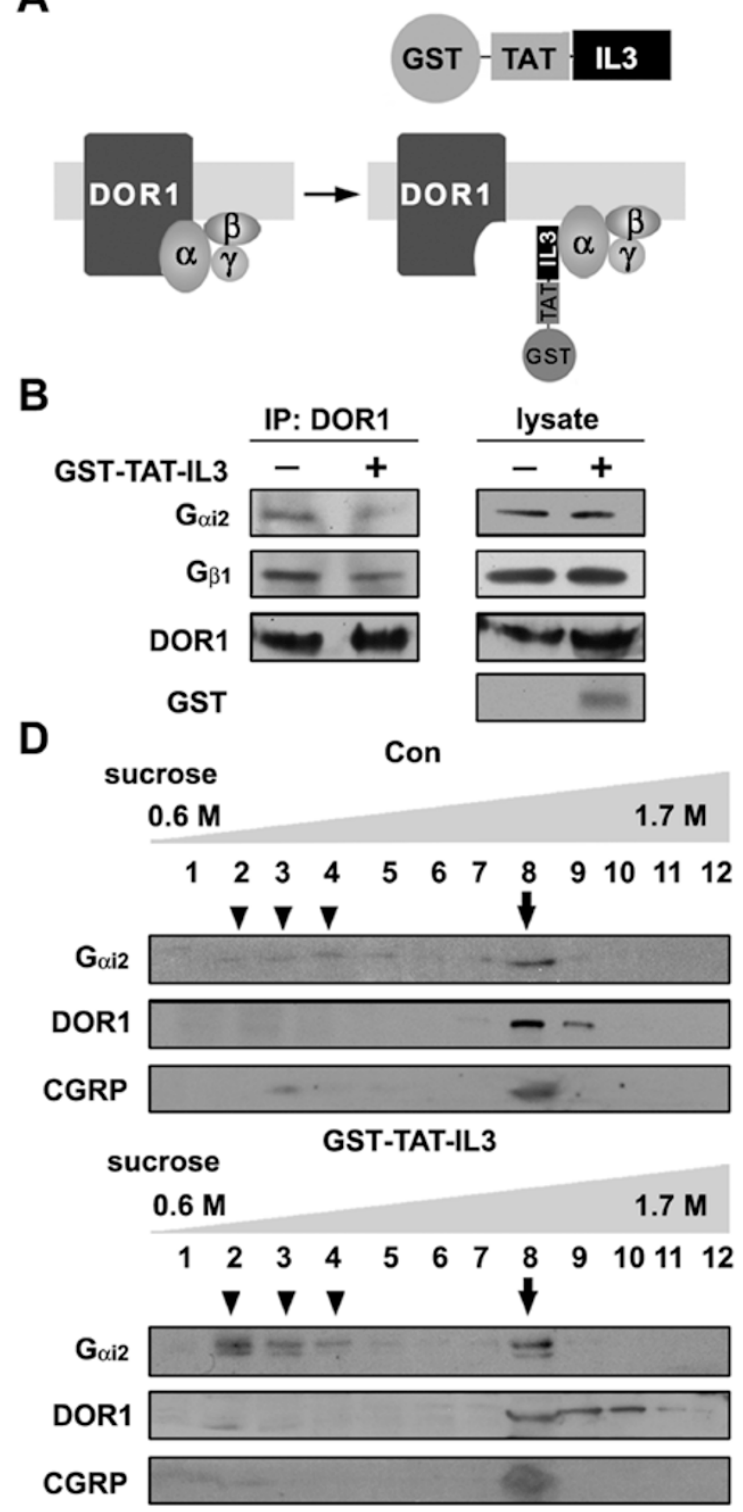

C

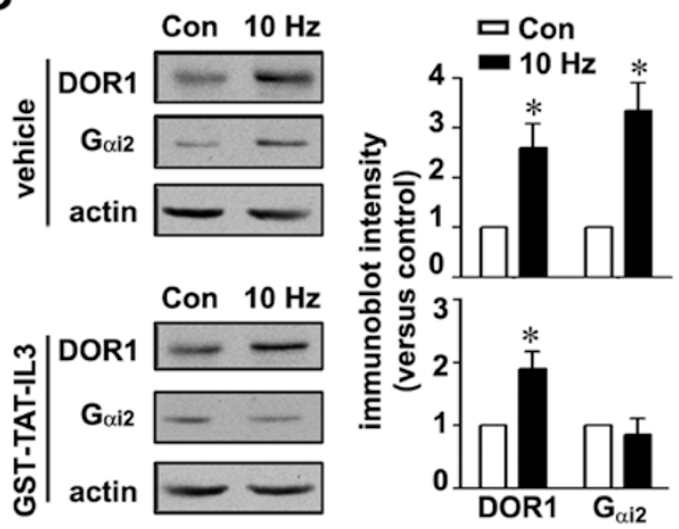

E
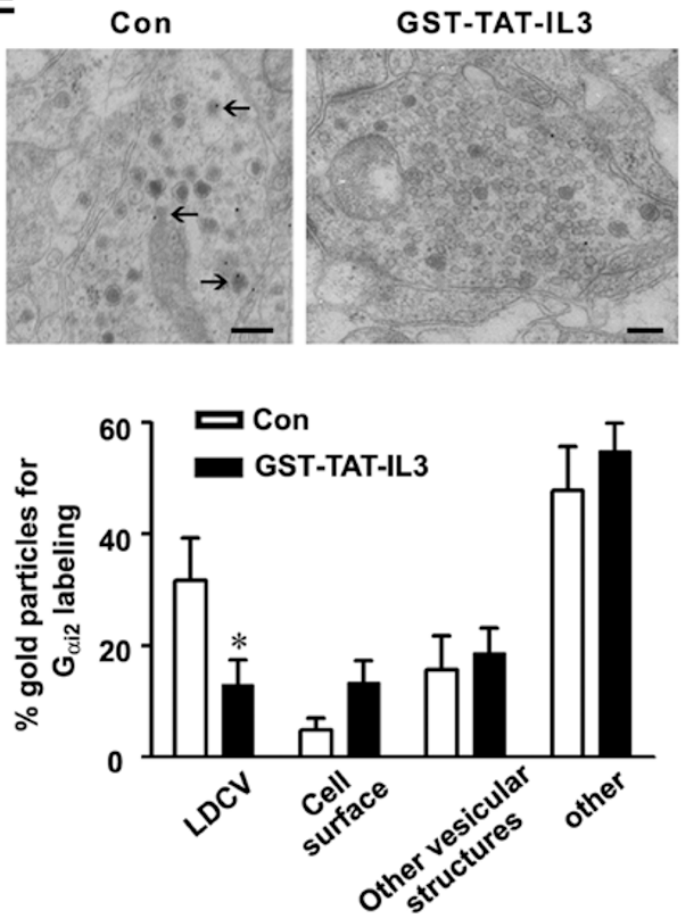

Figure 7 Dissociation of $G_{\text {oi } 2}$ from LDCVs by interrupting the DOR1/ $G_{\text {oi } 2}$ interaction. (A) Schematic model of GST-TAT-IL3 disruption of the DOR $1 / G_{\text {ci } 2}$ interaction. (B) Co-IP shows that the $D O R 1 / G_{\alpha i 2} / G_{\beta 1}$ association is attenuated in cultured DRG neurons incubated with GST-TAT-IL3 $(150 \mathrm{nM})$ for $6 \mathrm{~h}$. The GST-positive band indicates the permeation of GST-TAT-IL3. Three independent experiments were performed. (C) Cell-surface biotinylation and immunoblotting show that the surface expression of both DOR1 and $\mathrm{G}_{\text {ai2 }}$ is increased in cultured DRG neurons following 10-Hz electrical stimulation. After GST-TATIL3 treatment, $10-\mathrm{Hz}$ electrical stimulation enhanced surface expression of DOR1, but not $\mathrm{G}_{\text {ai2. }} * P<0.05$ versus control $(n=$ 4). (D) Immunoblot analysis of the extracts from the dorsal spinal cord of mice treated with GST-TAT-IL3 (i.p., $25 \mathrm{mg} / \mathrm{kg}$, once a day) for 4 days shows increased $G_{\text {ai } 2}$ in the fractions (arrowheads) lighter than the CGRP-positive vesicle fraction (arrow). Interestingly, the DOR1-containing fractions are not shifted. (E) Immunogold staining shows that the $\mathrm{G}_{\text {air }}$ labeling in LDCVs (arrows) in afferent terminals in spinal lamina II of control mice is reduced in the group of mice treated with GST-TAT-IL3. * $P$ $<0.05$ versus control group treated with vehicle ( $n=22$ terminals).

tant for sorting the receptor and its signaling molecules into LDCVs, which enables the rapid modulation of membrane properties in response to stimulation.

\section{Discussion}

The present study reveals that LDCVs function as a subcellular compartment not only for neuropeptides but 
also for GPCRs, ion channels and signaling molecules. In neurons, SVs and LDCVs are two types of regulated secretory vesicles. Stimulus-induced elevation of intracellular $\mathrm{Ca}^{2+}$ triggers exocytosis of SVs and LDCVs to discharge neurotransmitters and neuropeptides, respectively [1-3]. The presence of CGRP and vesicle traffickingrelated proteins in the LDCV-enriched fractions is consistent with current knowledge about the function of LDCVs. However, the present study suggests that LDCVs also play a considerable role in the delivery of receptors, ion channels and signaling molecules to the cell surface. When the exocytosis of LDCVs occurs, the molecules associated with their membranes can be expressed on the cell surface, enabling rapid modulation of the molecular and functional properties of the plasma membrane.

\section{Methodological considerations}

To interpret the present results, some methodological limitations of the vesicle isolation, LC-MS technology and post-embedding immunogold labeling had to be considered. First, in addition to the neuropeptide-containing LDCVs, which are enriched in the sensory afferent terminals, the LDCV fractions might also include other types of LDCVs, such as Piccolo-Bassoon transport vesicles, which have a dense-core appearance and a diameter of $80 \mathrm{~nm}$ [36-39]. The LDCV-enriched fraction contained Munc18-1, which is delivered to the presynaptic membrane via Piccolo-Bassoon transport vesicles $[37,39]$ to regulate the exocytosis of LDCVs [40]. However, the relationship between neuropeptide-containing LDCVs and the Piccolo-Bassoon transport vesicles in DRG neurons remains to be investigated. Second, the LC-MS methods may not detect all LDCV-associated proteins (i.e., proteins expressed at relatively low levels), including some key proteins. For example, DOR1, 5-HT-1D and other receptors could not be detected by LC-MS. Although other studies have measured VAMP1 and VAMP2 in LDCVs [20, 41, 42], we were able to detect only VAMP1 in the LDCV-enriched fraction. Therefore, it is necessary to combine the LC-MS method with other experimental approaches to gain a global view of the vesicle-associated proteins. Third, immunostaining for the proteins determined to be associated with LDCVs by LC-MS should be performed to determine their subcellular localization. For example, some olfactory receptors and vomeronasal receptors were found in the LDCV fractions, which was consistent with our previous report of the presence of these receptors in the cDNA library of DRGs [23] and the BioGPS database (http://biogps.gnf.org/). However, their subcellular distribution should be further evaluated with good antibodies against these receptors. Finally, the sensitivity of post-embedding immunogold labeling is limited by the embedding procedure and the affinity of antibodies. For example, the stimulus-induced cellsurface expression of $\mathrm{G}_{\alpha \mathrm{i} 2}$ was abolished by TAT-IL3, which interrupted the DOR $1 / \mathrm{G}_{\text {ai2 }}$ interaction, suggesting that most $\mathrm{G}_{a \mathrm{i} 2}$-containing LDCVs may contain DOR1. However, post-embedding double immunogold labeling showed that $\sim 53 \%$ of the $\mathrm{G}_{\mathrm{\alpha i2} 2}$-immunoreactive LDCVs in afferent terminals were also DOR1-positive. Therefore, the immunogold labeling might not show all the LDCVs that normally contain both DOR 1 and $\mathrm{G}_{a \mathrm{i} 2}$. Although there are some methodological limitations, the present study provides a general view of the LDCV membraneassociated proteins.

Neuropeptide secretion and cell-surface expression of receptors and channels

The present study shows the presence of multiple GPCRs in the membranes of LDCVs. In addition to DOR1 and 5-HT-1D [9, 12, 22], B1 BKR, $\beta 1$ AR, $\beta 2$ AR, NTR-2 and mGluR3 were identified in the LDCV fraction. Interestingly, the LDCV-associated receptors can be localized in two distinct subsets of LDCVs. The SP-positive subset of LDCV contained DOR1, 5-HT-1D and $\beta 2 \mathrm{AR}$, whereas $\beta 1 \mathrm{AR}$ was present in the LDCVs that did not contain either SP or CGRP. Interestingly, the latter subset of LDCVs was previously reported to account for $\sim 30 \%$ of all LDCVs in afferent terminals [24], suggesting that different subsets of LDCVs may deliver distinct sets of receptors to the cell surface.

Our previous studies have shown that the plasma membrane insertion of DORs, which are associated with SP- and CGRP-containing LDCVs in nociceptive sensory neurons, can be triggered by electrical stimulation [10] and various chemical stimulations, such as the treatment with DOR agonists, capsaicin and $\mathrm{K}^{+}$-induced membrane depolarization [9]. Presumably, the same stimulation would lead to the cell-surface expression of DORs, $\beta 2$ ARs, 5-HT-1D and P2X $\mathrm{X}_{2}$ because they were found in the same subset of LDCVs. The activity-dependent membrane insertion of these receptors would be coupled with the release of neuropeptide SP and CGRP. Moreover, DORs are sorted into LDCVs based on their interaction with the precursor protein of SP $[10,11,43]$, which suggests that the luminal content proteins of LDCVs may also contribute to mechanisms for sorting of membrane receptors [44-46]. Therefore, it would be interesting to investigate what kinds of neuropeptides are stored in the SP- and CGRP-negative LDCVs, which contain $\beta 1$ ARs and Wnt receptors. It would also be interesting to determine whether the exocytosis of this subset of LDCVs occurs with the SP- and CGRP-positive LDCVs or in a distinct manner. 
We observed the subunits of voltage-gated channels, such as VGCC $\alpha 2 \delta 1$ subunit and $\mathrm{K}_{\mathrm{V}} \beta 2$ subunit, in LD$\mathrm{CVs}$ without the pore-forming subunits. We propose that the LDCV-associated subunits of ion channels could be expressed on the cell surface when the exocytosis of LDCVs occurs in response to stimulation. These newly inserted subunits may interact with the pore-forming subunits that are already on the cell surface, which would enable the regulation of the channel properties. The mechanisms by which the newly inserted channel subunits regulate the activity of pore-forming subunits remain to be studied. Interestingly, we noticed the presence of several channels involved in the release of $\mathrm{Ca}^{2+}$ from intracellular $\mathrm{Ca}^{2+}$ stores or $\mathrm{Ca}^{2+}$ influx via VGCCs. Release of $\mathrm{Ca}^{2+}$ from intracellular $\mathrm{Ca}^{2+}$ stores can be triggered by activating $\mathrm{IP}_{3} \mathrm{Rs}$ and ryanodine receptors $[47$, 48]. The existence of these receptors (Supplementary information, Table S1) in LDCV membranes is consistent with the notion that LDCVs can serve as intracellular $\mathrm{Ca}^{2+}$ stores $[49,50]$. Noxious stimuli might increase the cell-surface expression of the LDCV-associated VGCC $\alpha 2 \delta 1$ subunit in nociceptive afferent terminals. The presence of the VGCC $\alpha 2 \delta 1$ subunit permits an enhancement of the membrane trafficking of VGCC $\alpha 1$ subunit, an increase in $\mathrm{Ca}^{2+}$ current amplitude, faster activation/ inactivation kinetics and a hyperpolarizing shift in the voltage dependence of activation [51]. Therefore, the LDCV-mediated mechanisms for regulating intracellular $\mathrm{Ca}^{2+}$ signaling may contribute to the kinetic diversity of $\mathrm{Ca}^{2+}$-dependent secretion of neurotransmitters and neuromodulators.

Preassembling of receptor/signaling molecule complexes in $L D C V S$

The present study provides evidence for preassembling of GPCR/signaling molecule complexes [13, 14]. In peptidergic small DRG neurons, DORs are associated with $\mathrm{G}_{\mathrm{\alpha i2} 2} / \mathrm{G}_{\beta 1 \gamma 5}$ in LDCVs, indicating that these DOR1/ G-protein complexes could be delivered to the cell membrane as preassembled signaling complexes in response to extracellular stimulation. This reaction might rapidly facilitate the receptor-mediated response when the exocytosis of LDCVs occurs. Furthermore, PLC $\beta 2$ is also present in the DOR1/G-protein complex in LDCV membranes, suggesting an association of the PLC-mediated phosphoinositide second-messenger pathway with the DOR1/G-protein complex. Activation of this pathway might produce $\mathrm{IP}_{3}$ to activate the $\mathrm{LDCV}$-associated $\mathrm{IP}_{3} \mathrm{R}$. Indeed, there could be a molecular and spatial basis for direct coupling of DOR 1 signaling to $\mathrm{IP}_{3} \mathrm{R}$-mediated $\mathrm{Ca}^{2+}$ release from LDCVs. The functional impact of this LDCV-based $\mathrm{Ca}^{2+}$ store-and-release system remains to be investigated.

Another possible receptor/signaling molecule complex in LDCVs is related to Wnt signaling. Fzd receptors, a class of seven-transmembrane proteins, are the receptors of Wnts. In the canonical Wnt signaling pathway, Wnt binds to Fzd and the associated co-receptor LRP5/6 to activate Dvl1, which inhibits the axin/glycogen synthase kinase $3 \beta /$ APC complex and stabilizes $\beta$-catenin [29-31]. In the present study, Fzd8, Dvl1, axin and $\beta$-catenin were present in a subset of LDCVs in small DRG neurons that did not contain SP or CGRP. The Wnt signaling pathway might be activated by Wnt expressed in the spinal cord and peripheral tissues $[52,53]$. Therefore, preassembling of receptor/signaling molecule complexes in LDCVs could be a mechanism for activity-dependent modulation of neuronal sensitivity.

\section{Functional implications}

In the present study, LDCVs were isolated from the dorsal spinal cord, which contains afferent $\mathrm{C}$ - and $\mathrm{A} \delta$ fibers of small DRG neurons. Immunostaining showed that many LDCV-associated receptors and ion channels were localized in small DRG neurons, suggesting that these membrane proteins contribute to a mechanism for rapidly modulating the sensitivity of nociceptive afferents to several neurotransmitters and neuromodulators. For example, stimulus-induced membrane insertion of DORs might enhance the effects of endogenous opioid peptides released from local neurons in the spinal dorsal horn. Such a mechanism may also have functional impact in pain therapies. Indeed, the VGCC $\alpha 2 \delta 1$ subunit serves as a target protein for gabapentin and pregabalin, drugs used for the clinical treatment of certain types of chronic pain [54-56]. The LDCV localization of VGCC $\alpha 2 \delta 1$ would enable a stimulus-induced cell-surface expression of this $\mathrm{Ca}^{2+}$ channel subunit. This reaction might enhance the effects of gabapentin during pain treatment. An enhanced effect could be induced for the LDCV-associated 5-HT-1D receptor [22, present study], which is a target protein of anti-migraine triptans. However, further experimental and clinical studies are needed to evaluate the clinical relevance and the mechanisms responsible for increased cell-surface expression of these LDCVassociated drug targets in vivo.

\section{Conclusion}

We conclude that LDCVs, in addition to their function in storage and secretion of neuropeptides, can serve as carriers of many receptors, ion channels and signaling molecules, including some preassembled receptor/ signaling molecule complexes. This property of LDCVs enables a rapid modulation of neuronal sensitivity in re- 
sponse to stimulation, which may contribute to both the physiological and pharmacological functions of neurons.

\section{Materials and Methods}

\section{Preparation of LDCVS and liquid chromatography-mass spectrometry (LC-MS)}

To study the proteins associated with the membranes of LDCVs, we isolated LDCVs as described previously [25] and selected the fractions labeled by LDCV markers for further analysis. Briefly, the spinal dorsal horns of rats were homogenized in buffer (320 mM sucrose, $4 \mathrm{mM}$ HEPES, pH 7.4) and centrifuged for 10 $\min$ at $1000 \times g$. Supernatant was collected and centrifuged for 15 $\min$ at $9200 \times g$. The pellet was re-suspended and centrifuged for $15 \mathrm{~min}$ at $10500 \mathrm{~g}$. The resulting pellet was re-suspended in lysis buffer $(5 \mathrm{mM}$ Tris/ $\mathrm{HCl}, \mathrm{pH} 7.4)$ with an additional 9 volumes of ice-cold $\mathrm{H}_{2} \mathrm{O}$ to osmotically lyse the synaptosomes for $30 \mathrm{~min}$, and this homogenate was centrifuged at $100000 \times g$ for $2 \mathrm{~h}$. The pellet was re-suspended in sucrose buffer $(200 \mathrm{mM}$ sucrose, 0.1 $\mathrm{mM} \mathrm{MgCl} 2,0.5 \mathrm{mM}$ EGTA, $10 \mathrm{mM}$ HEPES, $\mathrm{pH}$ 7.4) and layered onto a continuous sucrose gradient. In the first centrifugation step, the sucrose gradient ranged from 0.3 to $1.2 \mathrm{M}$ sucrose $/ 4 \mathrm{mM}$ HEPES (pH 7.4), and the samples were centrifuged at $100000 \times$ $g$ for $20 \mathrm{~min}$. Samples were collected, and equal-volume aliquots were analyzed by immunoblotting using antibodies against CGB (1:500; Santa Cruz) or DOR 1-60 (1:1 000; Santa Cruz). The LDCV fractions with both CGB- and DOR1-positive bands were diluted with $0.3 \mathrm{M}$ sucrose (final concentration of sucrose: $0.7 \mathrm{M}$ ) and centrifuged at $100000 \times g$ for $1 \mathrm{~h}$. The pellet was re-suspended in sucrose buffer, layered onto the second sucrose gradient (1.1 to 2.0 $\mathrm{M}$ sucrose) and centrifuged at $100000 \times g$ for $5 \mathrm{~h}$. Samples were collected, and antibodies against CGB or DOR $1^{1-60}$ were used to identify the LDCV-enriched fraction. Proteins associated with the LDCV membrane were extracted by the ProteoExtract ${ }^{\mathbb{Q}}$ Native Membrane Protein Extraction Kit (Merck) and analyzed by LCMS. We performed immunoblotting experiments for CGB and DOR1 in these subcellular fractions.

For one-step sucrose centrifugation, the synaptosome samples were prepared from the spinal dorsal horn of mice, and lysed for $30 \mathrm{~min}$. The homogenate was directly layered onto a continuous sucrose gradient (ranging from 0.6 to $1.7 \mathrm{M}$ ) and centrifuged at $100000 \times g$ for $5 \mathrm{~h}$. Samples were collected for immunoblotting.

\section{Immunoblotting}

Protein samples were separated by SDS-PAGE, transferred, probed with antibodies and visualized with enhanced chemiluminescence. Antibodies against DOR1 $1^{1-60}(1: 1000$; Santa Cruz), DOR1 $1^{3-17}$ (1:1 000; Chemicon), CGB (1:500; Santa Cruz), CGRP (1:500; DiaSorin), actin (1:100 000; Chemicon), $\mathrm{G}_{\text {oi2 }}$ (1:500; Santa Cruz), $G_{\beta 1}$ (1:2 000; Santa Cruz), PLC $\beta 2$ (1:400; Santa Cruz), $\beta 2$ AR (1:1 000; Santa Cruz), $\beta 1$ AR (1:1 000; Santa Cruz), NTR-2 (1:200; Santa Cruz), prostaglandin E2 receptor EP2 (1:500; Santa Cruz), EP3 (1:500; Santa Cruz), EP4 (1:500; Santa Cruz), Fzd8 (1:500; Everest Biotech), GALR1 (1:200; ADI), B1 BKR (1:200; Santa Cruz), mGluR3 (1:1 000; Abcam), mGluR7 (1:1 000; Millipore-Chemicon), VGCC $\alpha 2 \delta 1$ (1:500; Affinity BioReagents), EAAT2 (1:500; Novocastra Laboratories), cholecystokinin receptor B (1:200; Santa Cruz), voltage-dependent anion-selective channel protein 1 (1:500; Calbiochem), axin (1:500; Santa Cruz),
PDI (1:500; Santa Cruz), cytochrome C (Cyto C) (1:1 000; Santa Cruz), TrkA (1:1 000; ATS), transferring receptor (1:1 000; Invitrogen) and caveolin-1 (1:1 000; Santa Cruz) were used.

\section{Immunostaining}

Adult mice and cultured cells were fixed, sectioned and immunofluorescently stained according to our previous protocol $[9$, 12]. Briefly, adult male mice and cultured cells were fixed with $4 \%$ paraformaldehyde and $0.1 \%$ picric acid for $2 \mathrm{~h}$. Cryostat sections of DRGs were incubated with primary antibodies at $4{ }^{\circ} \mathrm{C}$ for $24 \mathrm{~h}$ prior to incubation with corresponding secondary antibodies conjugated with fluorescein or rhodamine (1:100; Jackson ImmunoResearch). Cultured DRG neurons were fixed in $4 \%$ paraformaldehyde and $0.1 \%$ picric acid for $15 \mathrm{~min}$ or in methanol for $10-30$ min. After three PBS washes, cells were labeled with the primary antibodies. We used antibodies against DOR $1^{3-17}$ (1:30 000; DiaSorin), $\mathrm{G}_{\text {ai2 }}\left(1: 100\right.$; Santa Cruz), $\mathrm{G}_{\beta 1}$ (1:200; Santa Cruz), $\mathrm{G}_{\gamma 5}$ (1:400; Santa Cruz), PLC $\beta 2$ (1:200; Santa Cruz), P2X 2 (1:1 000; Chemicon), Fzd8 (1:400; Everest Biotech), $\beta 1$ AR (1:400; Santa Cruz), $\beta 2$ AR (1:200; Santa Cruz), SP (1:500; Neuromics), CGRP (1:500; Biogenesis), Dvll (1:200; a gift from Dr. Zhen-Ge Luo), VGCC $\alpha 2 \delta 1$ (1:100; Affinity BioReagents) and Myc (1:500; a gift from Dr Jin-Qiu Zhou).

\section{Electron microscopy}

Three adult male mice were processed for post-embedding immunogold staining or pre-embedding immunogold-silver labeling according to our previous protocol $[9,24]$. Briefly, mice were deeply anesthetized and perfused with $10 \mathrm{ml}$ warm saline. This was followed by treatment with $20 \mathrm{ml}$ warm fixative solution, which contained $4 \%$ paraformaldehyde, $0.1 \%$ picric acid and $0.05 \%$ glutaraldehyde in $0.1 \mathrm{M} \mathrm{PB}$, and then $180 \mathrm{ml}$ of ice-cold fixative for $5 \mathrm{~min}$. The spinal cord was removed and put into ice-cold fixative for $2 \mathrm{~h}$ at $4{ }^{\circ} \mathrm{C}$. The lumbar segments of the spinal cord were cut into $200-\mathrm{nm}$ slices and passed through $1 \%$ osmic oxide for 30 min, dehydrated and embedded in Epon 812. Polymerization was carried out at $37^{\circ} \mathrm{C}$ for $12 \mathrm{~h}, 45^{\circ} \mathrm{C}$ for $12 \mathrm{~h}$ and $60^{\circ} \mathrm{C}$ for $24 \mathrm{~h}$. Ultra-thin sections were cut, and silver or silver-gray sections were collected on nickel grids (200 mesh). The sections on nickel grids were subjected to immunogold staining [24]. We used primary antibodies against DOR $1^{3-17}$ (1:2 000; DiaSorin), $\mathrm{G}_{\text {ai2 }}$ (1:100; Santa Cruz), $\mathrm{G}_{\beta 1}$ (1:200; Santa Cruz), $\mathrm{G}_{\gamma 5}$ (1:400; Santa Cruz), PLC $\beta 2$ (1:200; Santa Cruz), P2X 2 (1:1 000; Chemicon), Fzd8 (1:400; Everest Biotech), $\beta 1$ AR (1:400; Santa Cruz), $\beta 2$ AR (1:200; Santa Cruz), Dvl1 (1:200; a gift from Dr Zhen-Ge Luo), TRPV2 (1:100; Millipore-Chemicon), VGCC $\alpha 2 \delta 1$ (1:100; Affinity BioReagents), $\mathrm{IP}_{3} \mathrm{R}$ subtype 3 (1:100; BD Biosciences Pharmingen), $\beta$-catenin (1:200; Millipore-Chemicon), EAAT2 (1:50; Novocastra Laboratories), VGAT (1:100; Synaptic Systems) and EEA1 (1:200; BD Biosciences Pharmingen). Pre-embedding immunogold-silver labeling was performed with primary antibodies against Myc (1:1 000; a gift from Dr Jin-Qiu Zhou), $1.4 \mathrm{~nm}$ gold conjugated with secondary antibodies (1:100, Nanoprobes) and HQ SILVER ${ }^{\mathrm{TM}}$ enhancement kit (Nanoprobes) [9].

\section{Immunoprecipitation}

The LDCV-enriched fractions collected from sucrose centrifugation were lysed in ice-cold RIPA buffer $(150 \mathrm{mM} \mathrm{NaCl}, 30 \mathrm{mM}$ HEPES, $10 \mathrm{mM} \mathrm{NaF}, 1 \%$ Triton, $0.1 \%$ SDS). Co- IP was performed according to our previous protocol [11]. 


\section{Cell-surface biotinylation}

Neurons were incubated at $37{ }^{\circ} \mathrm{C}$ for $5 \mathrm{~min}$ in the presence of $40 \mathrm{mM} \mathrm{K}^{+}$or $10-\mathrm{Hz}$ electrical stimulation (voltage, $8-10 \mathrm{~V}$; duration, $0.5 \mathrm{~ms}$ ), and surface biotinylation was performed according to our previous protocol [9]. The immunoreactive bands were quantified with SigmaScan software. Quantification was based on at least three independent experiments. The data were analyzed by paired Student's $t$ test, and the values are reported as the mean \pm S.E.M.

\section{Plasmid constructs and GST-TAT-IL3 purification}

Mouse $\mathrm{G}_{\alpha \mathrm{i} 2}$ and $\mathrm{G}_{\mathrm{o}}$ were cloned into a pcDNA3.1A-Myc vector. Rat $\beta 2 \mathrm{AR}$ and $\mathrm{B} 1 \mathrm{BKR}$ were cloned into a pEGFP-N3-derived vector in which the Myc tag was substituted for EGFP. VGCC $\alpha 2 \delta 1$ was kindly provided by Dr Andrea Welling and subcloned into the pEGFP-N3-derived vector. $\mathrm{K}_{V}-\beta 2$, a gift from Dr David N Parcej, was subcloned into the pEGFP-N3-derived vector. Dv11Myc was kindly provided by Dr Zhen-Ge Luo, and P2X $\mathrm{X}_{2}$-Myc was a gift from Dr Li-Shuang Cao. The IL3 of DOR1 was cloned into a pGEX-KG-derived vector in which TAT was added to the Cterminus of GST. GST-TAT-IL3 was expressed and purified from Escherichia coli BL21 (DE3).

\section{Cell culture and transfection}

Pheochromocytoma (PC12) cells (ATCC) cultured in DMEM (GIBCO) containing 10\% horse serum and 5\% fetal bovine serum were transfected with $1 \mu \mathrm{g}$ plasmid/5 $\mu 1$ Lipofectin reagent (GIB$\mathrm{CO}$ ) in a $35-\mathrm{mm}$ dish and cultured in medium containing serum for 3-4 days.

\section{GST-TAT-IL3 treatment}

For the cultured DRG neurons, $150 \mathrm{nM}$ GST-TAT-IL3 was added to the culture medium twice at an interval of $3 \mathrm{~h}$. For the mice, $25 \mathrm{mg} / \mathrm{kg}$ GST-TAT-IL3 was injected (i.p., once a day) for 4 days.

\section{Statistical analysis}

Data were evaluated by Student's $t$ test, and differences were considered significant at $P<0.05$. Results are shown as the mean \pm S.E.M.

\section{Acknowledgments}

This work was supported by NNSFC (30770678 and $30621062)$, National Basic Research Program of China (2009CB522005,2007CB914501,2010CB912000 and 2011CBA00400) and CAS (GJHZ06).

\section{References}

1 De Camilli P, Jahn R. Pathways to regulated exocytosis in neurons. Annu Rev Physiol 1990; 52:625-645.

2 Hökfelt T, Bartfai T, Bloom F. Neuropeptides: opportunities for drug discovery. Lancet Neurol 2003; 2:463-472.

3 Hannah MJ, Schmidt AA, Huttner WB. Synaptic vesicle biogenesis. Annu Rev Cell Dev Biol 1999; 15:733-798.

4 Takamori S, Holt M, Stenius K, et al. Molecular anatomy of a trafficking organelle. Cell 2006; 127:831-846.

5 Blondeau F, Ritter B, Allaire PD, et al. Tandem MS analysis of brain clathrin-coated vesicles reveals their critical involvement in synaptic vesicle recycling. Proc Natl Acad Sci USA 2004; 101:3833-3838.

6 Waldhoer M, Bartlett SE, Whistler JL. Opioid receptors. Annu Rev Biochem 2004; 73:953-990.

7 Zhu Y, King MA, Schuller AG, et al. Retention of supraspinal delta-like analgesia and loss of morphine tolerance in $\delta$ opioid receptor knockout mice. Neuron 1999; 24:243-252.

8 Mennicken F, Zhang J, Hoffert C, Ahmad S, Beaudet A, O'Donnell D. Phylogenetic changes in the expression of delta opioid receptors in spinal cord and dorsal root ganglia. $J$ Comp Neurol 2003; 465:349-360.

9 Bao L, Jin SX, Zhang C, et al. Activation of delta opioid receptors induces receptor insertion and neuropeptide secretion. Neuron 2003; 37:121-133.

10 Wang HB, Zhao B, Zhong YQ, et al. Coexpression of $\delta$ - and $\mu$-opioid receptors in nociceptive sensory neurons. Proc Natl Acad Sci USA 2010; 107:13117-13122.

11 Guan JS, Xu ZZ, Gao H, et al. Interaction with vesicle luminal protachykinin regulates surface expression of $\delta$-opioid receptors and opioid analgesia. Cell 2005; 122:619-631.

12 Zhang X, Bao L, Arvidsson U, Elde R, Hökfelt T. Localization and regulation of the delta-opioid receptor in dorsal root ganglia and spinal cord of the rat and monkey: evidence for association with the membrane of large dense-core vesicles. Neuroscience 1998; 82:1225-1242.

13 Oldham WM, Hamm HE. Heterotrimeric G protein activation by G-protein-coupled receptors. Nat Rev Mol Cell Biol 2008; 9:60-71.

14 Galés C, Rebois RV, Hogue M, et al. Real-time monitoring of receptor and G-protein interactions in living cells. Nat Methods $2005 ; 2: 177-184$

15 Wagner JA. Structure of catecholamine secretory vesicles from PC12 cells. J Neurochem 1985; 45:1244-1253.

16 Loh YP, Kim T, Rodriguez YM, Cawley NX. Secretory granule biogenesis and neuropeptide sorting to the regulated secretory pathway in neuroendocrine cells. $J$ Mol Neurosci 2004; 22:63-71.

17 Huh YH, Jeon SH, Yoo SH. Chromogranin B-induced secretory granule biogenesis: comparison with the similar role of chromogranin A. J Biol Chem 2003; 278:40581-40589.

18 Iezzi M, Escher G, Meda P, et al. Subcellular distribution and function of Rab3A, B, C, and D isoforms in insulin-secreting cells. Mol Endocrinol 1999; 13:202-212.

19 Gerber SH, Rah JC, Min SW, et al. Conformational switch of syntaxin-1 controls synaptic vesicle fusion. Science 2008; 321:1507-1510.

20 Meng J, Wang J, Lawrence G, Dolly JO. Synaptobrevin I mediates exocytosis of CGRP from sensory neurons and inhibition by botulinum toxins reflects their anti-nociceptive potential. J Cell Sci 2007; 120:2864-2874.

21 Egger C, Kirchmair R, Kapelari S, Fischer-Colbrie R, HogueAngeletti R, Winkler H. Bovine posterior pituitary: presence of p65 (synaptotagmin), PC1, PC2 and secretoneurin in large dense core vesicles. Neuroendocrinology 1994; 59:169-175.

22 Potrebic S, Ahn AH, Skinner K, Fields HL, Basbaum AI. Peptidergic nociceptors of both trigeminal and dorsal root ganglia express serotonin 1D receptors: implications for the selective antimigraine action of triptans. $J$ Neurosci 2003; 23:10988- 
10997.

23 Xiao HS, Huang QH, Zhang FX, et al. Identification of gene expression profile of dorsal root ganglion in the rat peripheral axotomy model of neuropathic pain. Proc Natl Acad Sci USA 2002; 99:8360-8365.

24 Zhang X, Nicholas AP, Hökfelt T. Ultrastructural studies on peptides in the dorsal horn of the spinal cord - I. Co-existence of galanin with other peptides in primary afferents in normal rats. Neuroscience 1993; 57:365-384.

25 Wang HB, Guan JS, Bao L, Zhang X. Distinct subcellular distribution of delta-opioid receptor fused with various tags in PC12 cells. Neurochem Res 2008; 33:2028-2034.

26 McKenzie FR, Milligan G. $\delta$-opioid-receptor-mediated inhibition of adenylate cyclase is transduced specifically by the guanine-nucleotide-binding protein $\mathrm{G}_{\mathrm{i}} 2$. Biochem J 1990; 267:391-398.

27 Georgoussi Z, Leontiadis L, Mazarakou G, Merkouris M, Hyde K, Hamm H. Selective interactions between G protein subunits and RGS4 with the C-terminal domains of the $\mu$ - and $\delta$-opioid receptors regulate opioid receptor signaling. Cell Signal 2006; 18:771-782.

28 Zhang L, Tetrault J, Wang W, Loh HH, Law PY. Short- and long-term regulation of adenylyl cyclase activity by $\delta$-opioid receptor are mediated by $\mathrm{G \alpha}_{\mathrm{i} 2}$ in neuroblastoma N2A cells. Mol Pharmacol 2006; 69:1810-1819.

29 Yanagawa S, van Leeuwen F, Wodarz A, Klingensmith J, Nusse R. The dishevelled protein is modified by wingless signaling in Drosophila. Genes Dev 1995; 9:1087-1097.

30 Huang H, He X. Wnt/ $\beta$-catenin signaling: new (and old) players and new insights. Curr Opin Cell Biol 2008; 20:119-125.

31 Moon RT, Kohn AD, De Ferrari GV, Kaykas A. WNT and $\beta$-catenin signalling: diseases and therapies. Nat Rev Genet 2004; 5:691-701.

32 Scheerer P, Park JH, Hildebrand PW, et al. Crystal structure of opsin in its G-protein-interacting conformation. Nature 2008; 455:497-502.

33 Acharya S, Saad Y, Karnik SS. Transducin- $\alpha$ C-terminal peptide binding site consists of C-D and E-F loops of rhodopsin. J Biol Chem 1997; 272:6519-6524.

34 Schwarze SR, Ho A, Vocero-Akbani A, Dowdy SF. In vivo protein transduction: delivery of a biologically active protein into the mouse. Science 1999; 285:1569-1572.

35 Racké K, Burns F, Haas B, Niebauer J, Pitzius E. Frequencydependent effects of activation and inhibition of protein kinase $\mathrm{C}$ on neurohypophysial release of oxytocin and vasopressin. Naunyn Schmiedeberg's Arch Pharmacol 1989; 339:617624.

36 Zhai RG, Vardinon-Friedman H, Cases-Langhoff C, et al. Assembling the presynaptic active zone: a characterization of an active one precursor vesicle. Neuron 2001; 29:131-143.

37 Shapira M, Zhai RG, Dresbach T, et al. Unitary assembly of presynaptic active zones from Piccolo-Bassoon transport vesicles. Neuron 2003; 38:237-252.

38 Garner CC, Kindler S, Gundelfinger ED. Molecular determinants of presynaptic active zones. Curr Opin Neurobiol 2000; 10:321-327.

39 Sytnyk V, Leshchyns'ka I, Dityatev A, Schachner M. TransGolgi network delivery of synaptic proteins in synaptogenesis. J Cell Sci 2004; 117:381-388.
40 Voets T, Toonen RF, Brian EC, et al. Munc18-1 promotes large dense-core vesicle docking. Neuron 2001; 31:581-591.

41 Mizuta M, Kurose T, Miki T, et al. Localization and functional role of synaptotagmin III in insulin secretory vesicles in pancreatic beta-cells. Diabetes 1997; 46:2002-2006.

42 Peters CG, Miller DF, Giovannucci DR. Identification, localization and interaction of SNARE proteins in atrial cardiac myocytes. J Mol Cell Cardiol 2006; 40:361-374.

43 Ma GQ, Wang B, Wang HB, Wang Q, Bao L. Short elements with charged amino acids form clusters to sort protachykinin into large dense-core vesicles. Traffic 2008; 9:2165-2179.

44 Zhang X, Bao L, Ma GQ. Sorting of neuropeptides and neuropeptide receptors into secretory pathways. Prog Neurobiol 2010; 90:276-283.

45 Arvan P, Castle D. Sorting and storage during secretory granule biogenesis: looking backward and looking forward. Biochem J 1998; 332 (Part 3):593-610.

46 Kelly RB. Pathways of protein secretion in eukaryotes. Science 1985; 230:25-32.

47 Ferris CD, Huganir RL, Supattapone S, Snyder SH. Purified inositol 1,4,5-trisphosphate receptor mediates calcium flux in reconstituted lipid vesicles. Nature 1989; 342:87-89.

48 Zorzato F, Fujii J, Otsu K, et al. Molecular cloning of cDNA encoding human and rabbit forms of the $\mathrm{Ca}^{2+}$ release channel (ryanodine receptor) of skeletal muscle sarcoplasmic reticulum. J Biol Chem 1990; 265:2244-2256.

49 Mitchell KJ, Pinton P, Varadi A, et al. Dense core secretory vesicles revealed as a dynamic $\mathrm{Ca}^{2+}$ store in neuroendocrine cells with a vesicle-associated membrane protein aequorin chimaera. J Cell Biol 2001; 155:41-51.

50 Yoo SH, Oh YS, Kang MK, et al. Localization of three types of the inositol 1,4,5-trisphosphate receptor/ $\mathrm{Ca}^{2+}$ channel in the secretory granules and coupling with the $\mathrm{Ca}^{2+}$ storage proteins chromogranins A and B. J Biol Chem 2001; 276:4580645812.

51 Arikkath J, Campbell KP. Auxiliary subunits: essential components of the voltage-gated calcium channel complex. Curr Opin Neurobiol 2003; 13:298-307.

52 Liu Y, Wang X, Lu CC, et al. Repulsive Wnt signaling inhibits axon regeneration after CNS injury. J Neurosci 2008; 28:8376-8382.

53 Bayle J, Fitch J, Jacobsen K, Kumar R, Lafyatis R, Lemaire R. Increased expression of Wnt 2 and SFRP4 in Tsk mouse skin: role of Wnt signaling in altered dermal fibrillin deposition and systemic sclerosis. J Invest Dermatol 2008; 128:871-881.

54 Dworkin RH, O'Connor AB, Backonja M, et al. Pharmacologic management of neuropathic pain: evidence-based recommendations. Pain 2007; 132:237-251.

55 Bauer CS, Nieto-Rostro M, Rahman W, et al. The increased trafficking of the calcium channel subunit $\alpha_{2} \delta-1$ to presynaptic terminals in neuropathic pain is inhibited by the $\alpha_{2} \delta$ ligand pregabalin. J Neurosci 2009; 29:4076-4088.

56 Luo ZD, Chaplan SR, Higuera ES, et al. Upregulation of dorsal root ganglion $\alpha_{2} \delta$ calcium channel subunit and its correlation with allodynia in spinal nerve-injured rats. $J$ Neurosci 2001; 21:1868-1875.

(Supplementary information is linked to the online version of the paper on the Cell Research website.) 